\title{
A CÉSAR O QUE É DE CÉSAR: O PATRIMÔNIO ARQUEOLÓGICO NAS ORGANIZAÇÕES FORMAIS DO BRASIL
}

\begin{abstract}
Render unto Ceasar the things wich are Ceasar's: archaeological heritage in formal organizations of Brazil
\end{abstract}

\author{
Alejandra Saladino \\ Carlos Alberto Santos Costa ${ }^{2}$ \\ Elizabete de Castro Mendonça ${ }^{3}$
}

\section{RESUMO}

$\mathrm{Na}$ instituição do patrimônio cultural no Brasil, uma problemática adensa-se em tempos de consolidação da legislação ambiental e de uma agenda política de viés desenvolvimentista. A saber: a preservação e a gestão do patrimônio arqueológico. O objetivo deste artigo é refletir sobre tal aspecto a partir da análise da complexificação da instituição do patrimônio cultural resultante da criação de uma nova organização formal: o Instituto Brasileiro de Museus (IBRAM). Os resultados preliminares deste primeiro esforço reflexivo indicam que, para uma maior eficácia na utilização de instrumentos e práticas de preservação sobre o patrimônio arqueológico, é necessário delimitar seu campo de atuação e estabelecer claramente atribuições e competências, bem como um plano de ação articulado entre as organizações formais de instância federal.

Palavras-chave: Patrimônio Cultural; Patrimônio Arqueológico; Organizações Formais; IPHAN; IBRAM

\begin{abstract}
In times of consolidation of enviromental legislation and a political agenda of development bias, ther's a denser problem, namely the preservation and management of archaeological heritage. The objective of this paper is to discuss this aspect from the analysis of the complexity of the cultural heritage of the institution resulting from the creation of a new formal organization: the Brazilian Institute of Museums (IBRAM). Preliminary results indicate, this first effort, the effectiveness of conservation practices and tools on the archaeological heritage, the need to delimit the field of action, establish clear roles and responsibilities and an action plan articulated between the formal organizations of federal level.
\end{abstract}

Keywords: Cultural Heritage, Archaeological Heritage; Formal Organizations; IPHAN; IBRAM

\section{RESUMEN}

\footnotetext{
${ }^{1}$ Professora-Doutora da Universidade do Estado do Rio de Janeiro (UNIRIO) e museóloga no Museu da República (MR/Ibram) - alejandrasaladino@gmail.com

${ }^{2}$ Professor adjunto da Universidade Federal do Recôncavo da Bahia (UFRB) - solracoteb@gmail.com

${ }^{3}$ Professora-Doutora do Departamento de Estudos e Processos Museológicos (DEPM) e do Programa de PósGraduação em Museologia e Patrimônio (PPG-PMUS) da Universidade Federal do Estado do Rio de Janeiro (UNIRIO) - elizabete.mendonca@gmail.com
} 
En la institución del patrimonio cultural en Brasil, un problema se agranda en estos tiempos de consolidación de las leyes ambientales y de una agenda política de desarrollo, es decir, la preservación y la gestión del patrimonio arqueológico. El objetivo de este artículo es reflexionar sobre este problema a partir del análisis de la complejización de la institución del patrimonio cultural a causa de la creación de una nueva organización formal: el Instituto Brasileño de Museos (IBRAM). Los resultados preliminares de este primer esfuerzo de reflexión indican que, para una mayor eficacia en la utilización de instrumentos y prácticas de preservación sobre el patrimonio arqueológico, es necesario delimitar su campo de actuación y establecer claramente deberes y facultades y también desarrollar un plan de acción articulado entre las organizaciones formales de ámbito federal.

Palabras clave: Patrimonio Cultural; Patrimonio Arqueológico; Organizaciones Formales; IPHAN; IBRAM

\section{Apresentação}

No contexto decorrente da consolidação da legislação ambiental, da complexificação na produção de conhecimento científico que representa a Arqueologia de Contrato na reestruturação da instituição do patrimônio cultural no Brasil e do aumento quantitativo e qualitativo da massa crítica no campo da arqueologia brasileira, é possível perceber a tomada de consciência sobre a problemática da preservação do patrimônio arqueológico. Um inconteste indício deste panorama encontra-se na programação do XVI Congresso da SAB e do XVI Congresso Internacional da UISPP, realizados simultaneamente em Florianópolis em setembro de 2011, que revela um considerável aumento no número de reuniões (mesasredondas, simpósios temáticos e fóruns) dedicadas à reflexão sobre aspectos referentes ao destino do patrimônio arqueológico no país ${ }^{4}$.

Se nos primórdios da arqueologia brasileira, boa parte dos pesquisadores compreendia seus estudos como atos preservacionistas per se, hoje passados cinqüenta anos da homologação da Lei $\mathrm{n}^{\mathrm{o}} 3.924 / 61$, é ponto pacífico a necessidade de se criar instrumentos de proteção, estratégias e práticas de preservação mais eficientes e eficazes. Enfim, é premente a elaboração de políticas públicas claras para a preservação do patrimônio arqueológico. Para tal, faz-se mister que as organizações formais adquiram mecanismos fortes de desempenho das suas funções de forma adequada, que as tornem aptas à execução da

\footnotetext{
${ }^{4}$ Em um primeiro levantamento, é possível identificar, além do já tradicional "Encontro do IPHAN com arqueólogos" vinte reuniões, entre mesas-redondas, simpósios temáticos e fóruns (ver http://arqueoparque.com/@api/deki/files/22974/=PROGRAMA\%25c3\%2587\%25c3\%25830_GERAL_CONGR ESSO SAB - UISPP.pdf). Se partirmos do levantamento elaborado pela arqueóloga Camila Wichers (2010), podemos perceber um aumento de $100 \%$ no número de reuniões realizadas no Congresso realizado em 2011.
} 
fiscalização, conservação e extroversão, sem criar empecilhos para o desenvolvimento da arqueologia brasileira.

Compreendemos que a preservação e a gestão do patrimônio arqueológico são temas de grande complexidade, pois se relacionam com um conjunto de aspectos igualmente densos e em distintos estágios de desenvolvimento. Se a arqueologia brasileira é hoje tema de pauta da Casa Civil $^{5}$ e movimenta somas monetárias altíssimas - favorecendo a ampliação do mercado de trabalho do arqueólogo - a não regulamentação da profissão imprime sobre tal panorama zonas cinzentas que exigem um comportamento ético por parte do profissional e maior infra-estrutura para gerenciar tal categoria de patrimônio por parte das organizações formais, nomeadamente o Instituto do Patrimônio Histórico e Artístico Nacional (IPHAN) e o Instituto Nacional do Meio Ambiente (IBAMA).

Por tudo isso, propomos neste artigo refletir sobre o estado da arte do patrimônio arqueológico brasileiro a partir da análise da complexificação da instituição do patrimônio cultural resultante da criação de uma nova organização formal: o Instituto Brasileiro de Museus (IBRAM), bem como apontar aspectos incontornáveis para consolidação e fortalecimento das políticas públicas de preservação. Finalizamos sugerindo alguns caminhos, no sentido de fomentar o debate acerca das questões por nós apresentadas. Assim, objetivamos contribuir para a reflexão sobre as potencialidades e complexidades das políticas públicas do patrimônio cultural.

Antes, faz-se necessário expor claramente os princípios e perspectivas básicos desta reflexão. Consideramos que a arqueologia de contrato representa uma complexificação na produção de conhecimento científico decorrente da confluência das demandas políticoeconômico-sociais em outro patamar, mais tenso e disputado. Compreendemos ainda a idéia de instituição do patrimônio à luz do institucionalismo histórico, ou seja, enquanto conjunto de normas, convenções, disposições legais, organizações formais e distintos segmentos sociais estruturados na interseção de diferentes campos, como o jurídico-legal, o político, o econômico e o acadêmico.

Por outro lado, percebemos o aumento quantitativo e qualitativo da massa crítica no campo da arqueologia, graças à criação de novos cursos de graduação e pós-graduação e do próprio amadurecimento do campo.

Finalmente, consideramos que a preservação do patrimônio arqueológico envolve questões relativas aos campos econômico, jurídico-legal, e da gestão e da ética profissional.

\footnotetext{
${ }^{5}$ É tema de pauta da agenda desenvolvimentista.
} 


\section{O patrimônio arqueológico na instituição do patrimônio cultural: um brevíssimo panorama}

Podemos considerar que o discurso do patrimônio cultural no Brasil fundamenta-se na tentativa de mapear os traços identitários da sociedade brasileira. Esta operação se dá já no século XIX, com os museus e institutos históricos e geográficos regionais compreendidos enquanto verdadeiros espaços de legitimação de ideias e valorização de matrizes culturais (FERNANDES, 2010). Todavia, diversos estudos (FONSECA, 2005; NOGUEIRA, 2005; CHAGAS, 2006; SALADINO, 2011), consideram o Movimento Modernista e seus desdobramentos como um processo de delineamento da brasilidade. Vale dizer, que tal fenômeno caracteriza-se enquanto processo relacional e político, pautado em seleções e hierarquizações de variáveis culturais.

A variável arqueológica, naquela época considerada o conjunto de traços culturais dos grupos pré-cabralinos, era tema dos estudos novecentistas e também estava presente no discurso do patrimônio de Mário de Andrade, formalizado no anteprojeto do Serviço do Patrimônio Histórico e Artístico Nacional (SPHAN). O museólogo Mario Chagas (2006) lembra da proposta de criação de um Museu de Arqueologia vinculado ao SPHAN, espaço de pesquisa e preservação do patrimônio arqueológico brasileiro. A proposta foi rechaçada por importantes agentes do patrimônio da época, dentre os quais Heloisa Alberto Torres, diretora do Museu Nacional $(\mathrm{MN})$, que propôs uma parceria entre as organizações, com vistas à otimização de recursos e definição de competências. O antropólogo do MN, Luiz de Castro Faria, foi indicado pela diretora do museu para a coordenação dos registros de sítios arqueológicos e demais ações de proteção dessa categoria de bem, além da gestão da dotação orçamentária destinada às pesquisas arqueológicas (SALADINO, 2010).

Na década de 1960, o museólogo Theodoro Russins assumiu a arqueologia naquela organização formal. O agente, além de coordenar as ações supracitadas, colaborou na implantação de museus arqueológicos no país. Todavia, as instituições científicas brasileiras mantiveram-se colaboradoras da organização formal daquele órgão.

A partir do institucionalismo histórico, podemos perceber que as escolhas feitas no momento de implantação de uma organização formal são decisivas para a instauração de padrões institucionais, uma vez que a legitimam. Por isso, somente com grande esforço tais padrões são substituídos por outros ou se alteram (HALL e TAYLOR, 2003). No caso do 
IPHAN $^{6}$, identificamos o estabelecimento de parcerias com organizações científicas para o desenvolvimento de ações sobre o patrimônio arqueológico. É compreensível que tais convênios sejam implementados, uma vez que o conhecimento arqueológico ultrapassa as fronteiras e competências de uma organização de proteção do patrimônio. Contudo, considerando os desenhos institucionais do IPHAN ao longo de sete décadas ${ }^{7}$, nos quais podemos claramente perceber a inexistência de um setor específico para o patrimônio arqueológico até $1979^{8}$, podemos concluir que as referidas parcerias contribuíram para a tardia estruturação do IPHAN em relação ao patrimônio arqueológico (SALADINO, 2010). Os organogramas da instituição indicam a frágil estrutura dos setores criados para a gestão do patrimônio arqueológico, além de sua subordinação ao setor responsável pelas ações sobre o patrimônio edificado, estruturado na consolidação do padrão institucional de valorização do patrimônio pedra e cal (no plano simbólico, a valorização das representações vinculadas à matriz luso-católica).

Todavia, fatores exógenos à organização exigiam-lhe maior capacidade de atuação. O estabelecimento da Arqueologia de Contrato $^{9}$ e a consolidação da legislação ambiental ${ }^{10}$ impuseram ao IPHAN a necessidade de uma regulamentação das autorizações de pesquisas arqueológicas e da obtenção de maior aparato legal e de gestão para dar conta das demandas cada vez maiores. Como resultados, podemos apontar a elaboração da Portaria $n^{\circ}$ 07/88, da Portaria $n^{\circ}$ 230/02 e da Portaria $n^{\circ} 28 / 03$, evidenciando a ciclotimia que caracteriza a relação entre organização e arqueólogos, ora pautada no colaboracionismo e compreensão, ora nas disputas e conflitos - e as numerosas e assistemáticas ações com vistas a definir os estatutos conceituais e normativos das políticas públicas sobre o patrimônio arqueológico. A título de ilustração, apontamos como tais ações a promoção de encontros de toda ordem e de reuniões técnicas e a elaboração de programas e termos de referências. Alguns não alcançaram ressonância nas representações regionais do IPHAN - pelos mais distintos e variados motivos - enquanto outros tinham, por sua vez, abrangência apenas regional. Vale dizer que alguns motivos, à luz do institucionalsmo histórico, relacionam-se à precariedade dos recursos humanos e financeiros e, em última instância, às primeiras escolhas que determinaram

\footnotetext{
${ }^{6}$ A organização, ao longo de sete décadas, recebeu o estatuto de serviço, diretoria, instituto, secretaria, subsecretaria e novamente instituto.

${ }^{7}$ O SPHAN foi oficializado pela Lei ${ }^{\circ} 378$, de 13 de janeiro de 1937.

${ }^{8}$ Ano da contratação do primeiro arqueólogo para o quadro funcional do órgão.

${ }^{9}$ Podemos considerar que a Arqueologia de Contrato teve seu marco inicial no salvamento realizado no âmbito da construção da Hidrelétrica de Itaipu e encontra-se em franco desenvolvimento na esteira do Programa de Aceleração do Desenvolvimento (PAC).

${ }^{10}$ Cujo marco é a homologação da Resolução CONAMA no $001 / 86$, que atrelava os trabalhos arqueológicos ao licenciamento ambiental.
} 
padrões institucionais caracterizados pelo "esquecimento" do patrimônio arqueológico frente a outras demandas (SALADINO, 2010).

Algumas dessas exigências resultaram na atualização do discurso e reestruturação do desenho institucional do IPHAN. De concreto, podemos apontar a criação do Departamento de Patrimônio Imaterial (DPI/IPHAN) e do Departamento de Museus e Centros Culturais (DEMU/IPHAN), responsáveis pelo sucesso na consolidação e fortalecimento das políticas públicas do patrimônio de natureza imaterial e dos museus. O patrimônio arqueológico continuou atrelado à lógica inicial: a subordinação frente às ações sobre o patrimônio edificado, sob a coordenação do Departamento de Patrimônio Material e Fiscalização (DEPAM).

Este novo panorama - fundado na ampliação da categoria patrimônio, na diversificação dos discursos e no fortalecimento de outros segmentos intra-institucionais resulta do rearranjo das forças organizacionais e do estabelecimento de outras assimetrias. Desta vez, o patrimônio arqueológico parece estabelecido num cenário paradoxal e ambíguo: ora numa arena de disputa velada, ora no limbo do esquecimento não assumido. É importante lembrar que a consolidação do DEMU/IPHAN - graças à realização de concurso público em 2005, e ao crescimento de sua dotação orçamentária, bem como da própria Política Nacional de Museus (PNM) - resultou na identificação de um problema: a preservação do patrimônio arqueológico musealizado.

Os acervos arqueológicos, em crescimento exponencial na esteira da Arqueologia de Contrato (BRUNO e ZANETTINI, 2007; COSTA, 2007; SALADINO, 2010; WICHERS, 2010), passaram também a ser assunto do DEMU/IPHAN. No entanto, durante a existência desse departamento, não foram claramente definidas as bases conceituais nem as competências de cada organismo do IPHAN sobre tal categoria de bem. Vale mencionar, porém, a única diretriz à época para as ações do DEMU/IPHAN, resultantes de demandas externas: o material arqueológico retirado do contexto e depositado nos museus deveria ser objeto das ações e instrumentos de proteção daquele departamento.

Contudo, faz-se mister apontar a problemática que tal orientação provocou: de acordo com as portarias de guarda de materiais arqueológicos concedidos pelo próprio IPHAN, os museus não são as únicas organizações formais responsáveis pela musealização dos bens culturais, se compreendermos tal ação como a aplicação da cadeia operatória da museologia (ações e estratégias de salvaguarda, pesquisa e comunicação). Se levarmos em conta o estudo da arqueóloga e doutora em museologia Camila Moraes Wichers (2010), veremos que $41 \%$ dos endossos institucionais estão associados a laboratórios e centros de 
pesquisas. A pergunta que fica: acervos arqueológicos musealizados em laboratórios ou em outras instituições de pesquisa, então, não seriam assistidos pela atuação do DEMU/IPHAN? E outra pergunta, ainda: os sítios arqueológicos passíveis de musealização estariam apenas sob a responsabilidade e a orientação da Gerência de Patrimônio Arqueológico, vinculada ao Departamento de Patrimônio Material e Fiscalização (DEPAM/IPHAN)?

É importante ressaltar que, nesse contexto, e com o intuito de abrir o debate sobre toda a complexidade relacionada ao patrimônio arqueológico em museus, foram organizadas as discussões do Grupo de Trabalho Museus e Acervos Arqueológicos e Etnográficos no âmbito dos Fóruns Nacionais de Museus (FNM). Durante o III FNM - organizado pelo DEMU/IPHAN em 2008 na cidade de Florianópolis - foi criada a então Rede de Museus e Acervos Arqueológicos e Etnográficos (FNM, 2010: 95), composta atualmente por cerca de cento e vinte estudiosos e agentes comprometidos com a proposição de ações em prol da preservação do patrimônio arqueológico.

Todavia, é importante retroceder ao I FNM, quando o Grupo de Trabalho Museus Etnográficos e Arqueológicos levou à Plenária Final a moção nº 6 para:

solicitar a criação de um grupo temático de caráter permanente para questões de acervos e museus arqueológicos, contemplando em especial a questão das pesquisas empresariais, considerando a natureza expansionista da criação de coleções arqueológicas que demanda uma dinâmica própria e procedimentos museológicos (FNM, 2004: 62).

Finalmente, no IV FNM, realizado em 2010 em Brasília, foi atendida essa moção, o que resultou na reestruturação da rede criada em 2008 (FNM, 2008), nomeada, a partir de então, Rede de Museus e Acervos Arqueológicos (SALADINO et al., 2011).

Voltando ao panorama do IPHAN, vale dizer que a organização ganhou novos matizes quando da reestruturação do seu desenho institucional, que resultou na extinção do DEMU/IPHAN, na consequente criação do IBRAM $^{11}$ e no fortalecimento e organização de um setor dedicado às problemáticas do patrimônio arqueológico: o Centro Nacional de Arqueologia (CNA/IPHAN) ${ }^{12}$. Contudo, o CNA/IPHAN, estruturado em três coordenações Coordenação de Normas e Acautelamento, Coordenação de Pesquisa e Licenciamento e Coordenação de Socialização do Patrimônio Arqueológico - parece ainda não ter se distanciado dos padrões institucionais do IPHAN de hierarquização e priorização de algumas categorias de bens em relação às outras.

\footnotetext{
${ }^{11}$ Criado pela Lei $\mathrm{n}^{\mathrm{o}} 11.906$ de 20 de janeiro de 2009.

${ }^{12}$ Reestruturado através do Decreto n ${ }^{\circ} 6.844$ de 7 de maio de 2009.
} 
Permaneceu também o padrão dos insuficientes recursos humanos e financeiros destinados à gestão do patrimônio arqueológico frente às demandas acachapantes, se considerarmos o número de projetos que o setor deve acompanhar (BRUNO e ZANETTINI, 2007; WICHERS, 2010), bem como a elaboração e execução das demais ações de proteção e socialização do patrimônio arqueológico.

\section{O presente e o futuro: algumas constatações e caminhos possíveis}

No Brasil, a arqueologia teve nos museus estratégicas organizações formais para sua estruturação enquanto disciplina científica (SCHWARCZ, 2004). Por isso é comum ouvir que a arqueologia já nasceu musealizada. Em outras palavras, desde o início foi aplicada sobre o patrimônio arqueológico a cadeia operatória da museologia. De forma distinta do que ocorreu com a Antropologia no século XX - que de certa forma divorciou-se dos museus para ganhar outros espaços nos departamentos das universidades (DIAS, 2007) - a arqueologia mantevese nas organizações museológicas, muitas das quais também vinculadas a essa categoria de organização.

Por outro lado, conforme mencionado anteriormente, com o fortalecimento do setor museológico ocorrido na última década, além da consolidação do turismo cultural (com todas as suas nuances positivas e negativas), ocorreu uma maior conscientização sobre a estreita relação entre duas áreas do conhecimento, ambas essencialmente interdisciplinares e com foco de atuação na cultura material: arqueologia e museologia. Percebemos inclusive a museologia, enquanto ciência social aplicada, como sendo capaz de mudar a condição do patrimônio arqueológico na estratigrafia do abandono (BRUNO, 2005). Diversos agentes, boa parte reunidos na REMAAE, passaram a produzir e ampliar a área de interseção entre arqueologia e museologia. Devemos lembrar ainda o aumento da massa crítica em ambas as áreas, resultante da criação de novos cursos de arqueologia e museologia em nível de graduação e pós-graduação ${ }^{13}$.

Voltando ao patrimônio arqueológico no âmbito das organizações formais, é importante mencionar que o IBRAM optou por uma lógica de atuação institucional fundada no conceito de patrimônio museológico, sem evidenciar ou tratar especialmente as demandas

\footnotetext{
${ }^{13}$ Hoje dispomos de formação de graduação em museologia na UNIRIO, UFBA, UNIBAVE, UFRB, UFPEL, UFRGS, UFS, UFOP, UFMG, UNB, UFPE, UFPA, UFG, UFSC e FAECA DOM BOSCO, e pós-graduação stricto sensu (mestrado e doutorado) na UNIRIO/MAST, na USP e na UFBA. Com relação à formação em arqueologia, dispomos de graduação na UFPEL, UFS, UFPI, FURG, PUC-GO, UFPE, UNIR, UEA e UNIVASF, e pós-graduação stricto sensu (mestrado e/ou doutorado) na UFRJ, USP, UFPA, UFPE, UFPI, PUCRS e UFS. Um quadro analítico desta situação pode ser visto em Wichers (2010).
} 
das distintas categorias de bens. Assim, a Coordenação de Patrimônio Museológico do Departamento de Processos Museais (CPM/DPMUS/IBRAM), atua sobre as coleções arqueológicas em museus sem a configuração de um setor específico para tal.

Por tudo isso, acreditamos na necessidade de definir claramente diretrizes, protocolos, atribuições e competências para lograrmos mudar o estado da arte do patrimônio arqueológico brasileiro. Embora reconheçamos que o patrimônio cultural ultrapassa os limites das ações e instrumentos do Estado, compreendemos ser fundamental o fortalecimento e o cumprimento de suas recomendações. Após quatro anos de reestruturação institucional na instância federal, ainda não foi possível observar articulações concretas entre as organizações formais em prol da preservação do patrimônio arqueológico.

A divisão do cabido federal da cultura entre o IPHAN e o IBRAM fez com que as instituições, em seus novos modelos institucionais, tateassem na busca de um equilíbrio no que concerne aos limites de suas atuações com relação à gestão do patrimônio arqueológico. Como demonstramos, cabe ao IPHAN na atual conjuntura a tarefa de controlar e fiscalizar os trabalhos arqueológicos em toda a sua cadeia operatória, da pesquisa à extroversão; não é demais ressaltar que as etapas que correspondem à socialização deste legado são mal legisladas e, desta forma, constituem flancos abertos na proteção do patrimônio arqueológico. É justamente nesta ausência que percebemos a necessidade de uma ação incisiva do IBRAM para fazer valer as suas atribuições legais, que correspondem especificamente às etapas de musealização do patrimônio arqueológico.

$\mathrm{Na}$ esfera legal, esta divisão constitui limites estanques. Contrariamente, na esfera lógica e na prática, não existem estes limites, uma vez que as ações são por natureza sempre continuadas e processuais. Isto ocorre porque na cadeia operatória da formação dos acervos arqueológicos interessa àqueles que fazem as pesquisas arqueológicas qual destinação será dada aos acervos, bem como interessa aos que procedem a extroversão destes acervos de que modo ocorreram as pesquisas: os agentes de ambas as fases são os mesmos. Este mesmo princípio de interesse e ação mútua deve se aplicar à gestão pública dos acervos arqueológicos.

Desta maneira, não nos parece lógica a criação de distinções - separações estanques de ações entre agentes institucionais com interesses correlatos - senão buscar a sinergia que há nas ações de ambos os órgãos. Para ser mais explícitos, estamos falando da necessidade de uma gestão conjunta do patrimônio arqueológico, na qual a tutela é compartilhada entre o IPHAN e o IBRAM, no sentido de promoverem ações que auxiliem na proteção do patrimônio arqueológico pelo Estado, envolvendo as comunidades e, portanto, os interesses 
sociais. Dentre tantas questões que envolvem a gestão do patrimônio arqueológico, de maneira precisa entendemos como necessária a condução de algumas ações:

1 - A reunião entre IPHAN, IBRAM, comunidade museológica, comunidade arqueológica e instituições museais, no sentido de criar patamares de diálogo que sejam, de fato, coerentes com os diferentes atores envolvidos na gestão pública do patrimônio arqueológico;

2 - Do ponto de vista legal há a necessidade de conceituar o que se entende por "pesquisa arqueológica", por "acervo arqueológico" e por "guarda de acervos arqueológicos", incluindo-se nestas definições todas as etapas da cadeia operatória da formação dos acervos, desde o planejamento da pesquisa aos procedimentos de extroversão. No que concerne aos acervos arqueológicos, cabe dizer que na sua definição deve se incluir toda a documentação que permita compreender o contexto no qual foram coletados e, sobretudo, manter o fundo documental;

3 - A revisão dos procedimentos de endosso institucional, com o intuito de dar participação ativa às instituições museais na tramitação dos processos de guarda de materiais arqueológicos, já que na proteção legal permanente do patrimônio arqueológico são as instituições museais parceiras diretas da União;

4 - A revisão das normativas de concessão de pesquisa arqueológica, que incluam claramente parâmetros de extroversão e uso social público dos materiais sob a guarda institucional (elaboração de mídias, publicações, exposições, mostras, educação patrimonial, criação de instituições museais, uso continuado do patrimônio etc.);

5 - Frente à crescente demanda por espaços de guarda de acervos arqueológicos, que correspondem a gastos continuados de manutenção, há a necessidade da elaboração de parâmetros de seleção e descarte de acervos arqueológicos durante o processo de formação dos acervos, pois sua coleta indiscriminada atulha as reservas institucionais;

6 - No sentido de convergir de maneira ágil ações do IPHAN, do IBRAM e dos diferentes agentes envolvidos na geração dos acervos arqueológicos (instituições museais, arqueólogos, museólogos etc.), faz-se urgente a criação de uma base de dados nacional de gerenciamento dos acervos arqueológicos. Se por um lado, este meio permitiria a gestão ágil dos acervos, por outro, possibilitaria colocar à disposição de toda a sociedade os acervos existentes em território nacional ${ }^{14}$.

\footnotetext{
${ }^{14}$ Estas proposições foram amplamente debatidas durante a reunião da REMAAE nos I, II III e IV FNM (Salvador, 2004; Ouro Preto, 2006; Florianópolis, 2008 e Brasília, 2010), durante o Simpósio Temático "REMAAE: desafios para uma política de preservação do patrimônio arqueológico" realizado no XVI Congresso Nacional da SAB (2011) e também nas discussões entre os membros da rede no remaae@googlegroups.com.
} 
Enquanto isso não se concretiza, padrões institucionais viciados são fortalecidos e mesmo importados. Além disso, os agentes institucionais não se beneficiam da expertise de seus colegas de outras organizações e acabam agindo sempre de forma a buscar "reinventar a roda". A desarticulação e a falta de comunicação entre as organizações formais na instância federal, responsáveis pela proteção e valorização do patrimônio arqueológico, ficam patentes em levantamentos feitos por pesquisadores que se debruçam sobre o tema (BRUNO e ZANETTINI, 2007; WICHERS, 2010), que demonstram a assimetria entre a lista de instituições fiéis depositárias de material arqueológico, resultante das portarias emitidas pelo IPHAN, e a lista emitida pelo Cadastro Nacional de Museus do IBRAM ${ }^{15}$.

\section{Considerações finais}

Nas últimas décadas, a instituição do patrimônio cultural no Brasil passou por importantes mudanças. Em tempos de sedução de memória (Huyssen, 2000) e "neurose do patrimônio" (Jorge, 2005) urge definir claramente fundamentos teórico-metodológicos e atribuições e competências de todos os segmentos envolvidos. As organizações formais têm decididamente um papel fundamental e estratégico nisso tudo ${ }^{16}$. A recuperação das suas memórias institucionais, a definição dos seus papéis e tarefas e a articulação com os demais segmentos (sociedade civil organizada, comunidade acadêmica, empreendedores etc.) são incontornáveis, inclusive para que os demais segmentos igualmente assumam seus papéis. Conforme o $\S 1^{\circ}$ do Art. 216, à sociedade compete colaborar com o poder público promover e proteger o patrimônio cultural brasileiro. No entanto, cabe ao Estado criar as bases para um efetivo ativismo. Disto não escapa um real colaboracionismo entre as organizações formais, pois os problemas do patrimônio arqueológico não são de uma ou de outra organização, mas de ambas. Afinal, as estratégias do IPHAN sobre o patrimônio arqueológico relacionam-se às do IBRAM e vice-versa. Acreditamos, que desta forma - com uma sociedade com forte consciência de cidadania (com indivíduos cientes de seus direitos, desejos e possibilidades) e com a consolidação da instituição do patrimônio cultural - poderá ser alcançado um patamar onde as demandas e os interesses político-econômico-sociais coloquem-se de forma mais equilibrada.

\footnotetext{
${ }^{15}$ Das 568 instituições envolvidas com a gestão de acervos arqueológicos, apontadas nas portarias de pesquisa homologadas pelo IPHAN e no Cadastro Nacional de Museus (CNM), apenas 9\% dessas organizações indicadas em ambas as fontes, o que revela a baixa conectividade (WICHERS, 2010:196) entre as mesmas.

${ }^{16}$ Cabe lembrar que de acordo com a Constituição Federal Brasileira de 1988 o patrimônio arqueológico é considerado bem da União (COSTA, 2007).
} 


\section{Referências bibliográficas}

BRUNO, Cristina; ZANETTINI, Paulo. Relatório do Simpósio O futuro dos acervos do XIV Encontro Nacional da Sociedade de Arqueologia Brasileira. Florianópolis: Universidade Federal de Santa Catarina, 2007.

CHAGAS, Mario de Souza. "A vida social e política dos objetos de um museu" In: Anais do Museu Histórico Nacional, vol.34. Rio de Janeiro: Ministério da Cultura / IPHAN, 2002.

COSTA, Carlos Alberto Santos. “A legalidade de um equívoco: acerca dos processos legais para a guarda de materiais arqueológicos em instituições museais" In: Anais do I Congresso Internacional de Arqueologia da SAB e XIV Congresso Nacional da SAB. Erechim: Habilis, 2007, 15p. (CD Room).

COSTA, Carlos Alberto Santos. "Gestão de acervos arqueológicos: considerações sobre a perspectiva legal" In: Canindé - Revista do Museu Arqueológico de Xingó (edição especial). Aracaju: MAX/UFS (no prelo).

DIAS, Nélia. “Antropologia e museus: que tipo de diálogo?” In: ABREU, Regina; CHAGAS, Mário de Souza; SANTOS, Myrian Sepúlveda dos. Museus, coleções e patrimônios: narrativas polifônicas. Rio de Janeiro: Garamond, MinC/IPHAN/DEMU, 2007, p.126-137.

FERNANDES, José Ricardo Oriá. "Muito antes do SPHAN: a política do patrimônio histórico no Brasil (1838-1937)" In: Anais do Encontro Politicas Culturais: teoria e praxis. Rio de Janeiro: Fundação Casa de Rui Barbosa, 2010.

FONSECA, Maria Cecília Londres. O patrimônio em processo: trajetória da política federal de preservação no Brasil. Rio de Janeiro: Editora UFRJ; MinC - Iphan, 2005.

Fórum Nacional de Museus (2004: Salvador, Bahia, BA). A imaginação museal: os caminhos da democracia. Relatório. Ministério da Cultura, Ministério da Cultura, Instituto do Patrimônio Histórico e Artístico Nacional, Departamento de Museus e Centros Culturais. Brasília, DF: MinC/IPHAN/DEMU, 2004.

Fórum Nacional de Museus (2006: Ouro Preto, Minas Gerais, MG). O futuro se constrói hoje. Relatório. Ministério da Cultura, Ministério da Cultura, Instituto do Patrimônio Histórico e Artístico Nacional, Departamento de Museus e Centros Culturais. Brasília, DF: MinC/IPHAN/DEMU, 2004.

Fórum Nacional de Museus (2008: Florianópolis, Santa Catarina, SC). Museus como agentes de mudança social e desenvolvimento Relatório. Ministério da Cultura, Instituto do Patrimônio Histórico e Artístico Nacional, Departamento de Museus e Centros Culturais. Brasília, DF: MinC/IPHAN/DEMU, 2010.

HALL, Peter; TAYLOR, Rosemary. "As três versões do neo-institucionalismo" In: Scielo Brasil. http://www.scielo.br/scielo.php?script=sci_arttext\&pid=S0102-64452003000100010 (último acesso: 02/09/2007)

HUYSSEN, Andréas. Seduzidos pela memória. Rio de Janeiro: Aeroplano, 2000. 
JORGE, Vítor Oliveira. "Património, neurose contemporânea? Alguns apontamentos sobre o papel da memória colectiva na Idade da Fragmentação" In: JORGE, Vítor Oliveira (coord.) Preservar para quê? 8 a Mesa Redonda de Primavera, Faculdade de Letras da Universidade do Porto. Porto: Centro de Estudos Arqueológicos das Universidades de Coimbra e PortoCEAUCP/Fundação para a Ciência e Tecnologia, 2005, p. 13-26.

NOGUEIRA, Antonio Gilberto Ramos. Por um inventário dos sentidos: Mário de Andrade e a concepção de patrimônio e inventário. São Paulo: Hucitetc, FAPESP, 2005.

SALADINO, Alejandra. Prospecções: o patrimônio arqueológico nas práticas e trajetória da IPHAN. Tese de Doutorado do Programa de Pós-Graduação em Ciências Sociais, Rio de Janeiro: UERJ, 2010.

SALADINO, Alejandra; COMERLATO, Fabiana; RIBEIRO, Diego Lemos. "Rede de Museus e Acervos Arqueológicos: ativismo para a preservação do patrimônio arqueológico" In: Caderno de Resumos do II Encontro Latino-americano de Arqueologia (resumo expandido). Rio de Janeiro: Centro de Arqueologia Brasileira, 2011:58-60.

SCHWARCZ, Lilia Moritz. O espetáculo das raças. São Paulo: Cia. Das Letras, 2004.

WICHERS, Camila Azevedo de Moraes. Museus e os descaminhos do patrimônio arqueológico: (des)caminhos da prática brasileira. Tese de doutorado apresentada ao Programa de Pós-Graduação em Museologia. Lisboa: Universidade Lusófona de Humanidades e Tecnologias, 2010. 